\title{
Insulated Wire Fed Floating Monopole Antenna for Coastal Monitoring
}

\author{
Zia M. LONI, Hugo G. ESPINOSA, David V. THIEL \\ School of Engineering, Griffith University, Brisbane, Australia \\ h.espinosa@griffith.edu.au
}

Submitted September 26, 2017 / Accepted March 5, 2018

\begin{abstract}
A thin, flexible, insulated wire submerged in seawater forms a coaxial cable which has attenuation at ultra-high frequency (UHF) dependent on the operating frequency, the diameter of the insulating material and the diameter of the inner conductor. An extension of the insulated wire above the surface through a spherical float forms a monopole antenna. Attenuation through the wire depends on the conductivity and temperature of seawater. This paper reports the effect of electromagnetic (EM) wave propagation at $433 \mathrm{MHz}$ through insulated wires with different radii of the insulating material and inner conductor. The attenuation was calculated and measured in the range of 32-47 $\mathrm{dB} / \mathrm{m}$. The propagation from the monopole antenna to a fixed shore based receiver was measured to be approximately equal to $1 \mathrm{~dB} / \mathrm{m}$. The propagation measurements were compared with a shielded coaxial cable. Results show that the propagation range depends on the ratio of the insulation radius to conductor radius for insulated wire, however, a shielded coaxial cable showed no significant attenuation. The technique has applications in coastal wireless sensor networks where the water depth changes continually due to tide and wave motion.
\end{abstract}

\section{Keywords}

Floating monopole antenna, ocean wave propagation, wireless sensor networks, insulated wire transmission

\section{Introduction}

In recent years, an interest in monitoring coastal parameters such as conductivity, temperature, and water flow has expanded to the use of distributed wireless sensor networks to develop three spatial dimensional maps in time. Communications between sensors can take many different forms. In the case of radio wave propagation the options include:

- Wireless underwater propagation

- Wired underwater propagation

- Wireless across the water surface

While underwater radio wave propagation is essentially impossible due to high attenuation, the other two aforementioned methods require wired propagation either through water or to the surface [1], [2]. Radio communications in the extremely low frequency (ELF) range have been used for military applications, i.e. submarine signaling, however, applications have been extended to commercial and scientific purposes. This includes applications related to oil and mineral exploration and pollution sensing in coastal areas. A completely submerged antenna (working frequency of $433 \mathrm{MHz}$ ) results in a very short propagation range (several centimeters). A significant propagation range through saline water could only be achieved by reducing the frequency or increasing the transmit power [3], [4].

Shammaa et al. [3] conducted experiments at lower $\mathrm{MHz}$ frequency range with completely submerged transceivers. They proposed that a frequency range between 1 to $20 \mathrm{MHz}$ is most suitable for underwater communication provided the transmit power is high i.e. $5 \mathrm{~W}$. Jimenez et al. [5] performed simulations and experiments at $100 \mathrm{kHz}$ with loop antennas placed horizontally on seabed. The seabed has lower conductivity and an EM wave can travel longer distances through seabed as compared to seawater. He reported that the wave attenuation through the seabed was lower than through seawater. Datsko et al. [6] performed experiments using a frequency range $5-30 \mathrm{MHz}$. He placed a transmitter and receiver over the seawater surface at heights of $30 \mathrm{~m}$ and $3 \mathrm{~m}$ respectively. He observed the effect of the ground reflected wave on the received power under different weather conditions which included wind force, direction and sea roughness. Milford et al. [7] performed experiment with insulated wire submerged in seawater. His experiments regarding attenuation in an insulated wire showed good agreement with theoretical modeling up to $300 \mathrm{MHz}$. Lee et al. [8] performed experiments to establish a microwave link over seawater surface by placing transceivers at variable heights $(0.37-1.83 \mathrm{~km})$. They performed statistical analysis and applied an empirical modeling of the measured data using Gaussian and Rician distribution functions. Zhao et al. [9] performed experiments at $8 \mathrm{GHz}$ to determine the effect of sea roughness resulting from wind speed. For smooth sea surface (wind speed of $0 \mathrm{~m} / \mathrm{sec}$ ), the relative error in $\mathrm{dB}$ 's was calculated as $1.2 \%$. However, for the wind speed of $10 \mathrm{~m} / \mathrm{sec}$, the relative error was $8.7 \%$. 


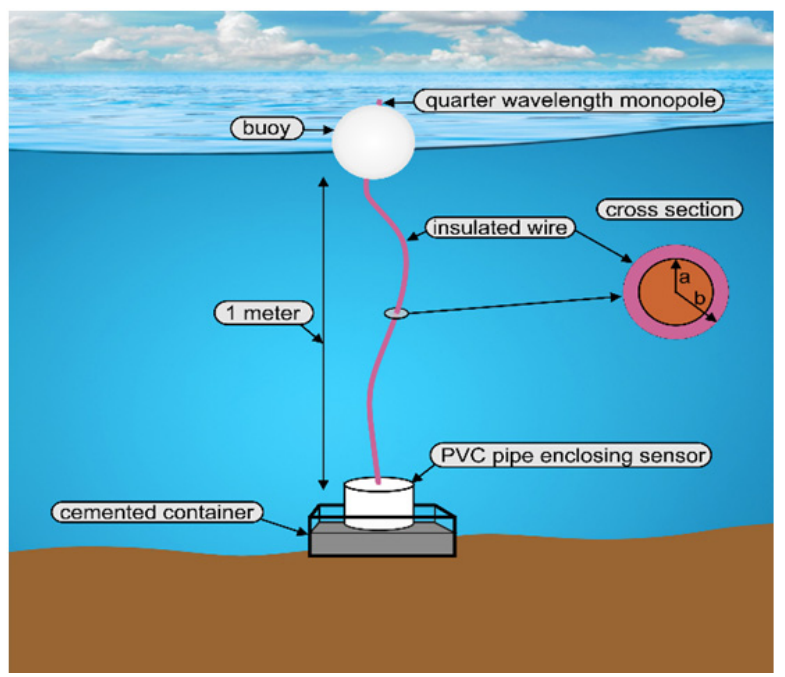

Fig. 1. Floating monopole antenna above a tethered seawater sensor enclosed by a PVC cylindrical pipe and cemented in a plastic container. Wires (insulated and shielded coax) passed from the sensor through the water to a Styrofoam float to form a floating monopole above the sea surface.

An insulated wire in the ocean serves as a transmission line where the conductive ocean water provides the outer conductor of the "coaxial" transmission line. This paper reports the characteristics of subsurface insulated wires. A complete configuration is shown in Fig. 1 with a weighted plastic container holding an air-filled PVC pipe which contains the sensor node and transmitter circuit. A flexible insulated wire was attached to the sensor node passing through the PVC pipe and extended to the surface of the seawater, protruding above it in a Styrofoam float that forms the floating monopole. The monopole length was equal to the diameter of the sphere, $12.5 \mathrm{~cm}$ and approximated a quarter wavelength monopole at $433 \mathrm{MHz}$.

Three commonly available, low cost connecting wires with PVC insulation with different radii of the insulation and inner conductor were investigated. Since the submerged part of the insulated wire forms a coaxial cable with water as outer conductor, results were compared with a shielded coaxial cable. The seawater characteristics, i.e. conductivity and temperature, were measured. These values were used to determine the permittivity of seawater [10], [11]. The attenuation of $433 \mathrm{MHz}$ through the submerged insulated wire in seawater was calculated using the methodology discussed by King and Smith [12], [13]. The calculated results were validated from reflection and transmission measurements in the laboratory. Field measurements were performed at the seashore to investigate the propagation range across the sea surface due to the protruding monopole antenna using three different insulated wires and the shielded coaxial cable.

The theoretical and experimental results discussed in this paper also predict the attenuation at lower ISM bands e.g. $6.7 \mathrm{MHz}$. A lower ISM band would result in a reduced attenuation coefficient. However, the size of the floating monopole would increase significantly. The proposed analysis offers an advance in coastal monitoring, as it allows
2D/3D subsurface measurements by an array of subsurface sensors connected via communications links between floating antennas.

The paper is organized as follows: Section 2 discusses the numerical modeling and simulated results for different insulated wire submerged in seawater. Section 3 reports the setup and results for laboratory and field measurements. Section 4 summarizes the work and provides recommendations for future implementations.

\section{Methodology and Numerical Simulations}

The attenuation and impedance of the submerged part of the insulated wire were determined. The propagation coefficient $\gamma$ and characteristic impedance $Z_{\mathrm{c}}$ of an insulated wire submerged in seawater (see Fig. 1) are given by [12], [13], [14],

$$
\gamma=\alpha+\mathrm{j} \beta=\mathrm{j} k_{\mathrm{L}}
$$

where $\alpha$ and $\beta$ are the attenuation and phase constant, respectively. Here $k_{\mathrm{L}}$ is defined as

$$
\begin{aligned}
& k_{\mathrm{L}}=k_{\mathrm{i}} \sqrt{\frac{h_{\mathrm{o}}+k_{\mathrm{e}} b \ln (b / a) h_{1}}{\left(k_{\mathrm{i}} / k_{\mathrm{e}}\right)^{2} h_{\mathrm{o}}+k_{\mathrm{e}} b \ln (b / a) h_{1}}}, \\
& Z_{\mathrm{c}}=\frac{\eta_{\mathrm{i}}}{2 \pi} \frac{k_{\mathrm{L}}}{k_{\mathrm{i}}}\left(\ln (b / a)+\left(\frac{k_{\mathrm{i}}}{k_{\mathrm{e}}}\right)^{2} \frac{1}{k_{\mathrm{e}} b} \frac{h_{\mathrm{o}}}{h_{1}}\right)
\end{aligned}
$$

where $a$ and $b$ are the radii of inner conductor and the insulation, respectively, and $k_{\mathrm{i}}$ and $k_{\mathrm{e}}$ correspond to the complex wave numbers representing the insulation and seawater. Here $\eta_{\mathrm{i}}$ is the impedance of insulating material and $h_{\mathrm{o}}=H_{n}{ }^{(2)}\left(k_{\mathrm{e}} b\right)$ where $H_{n}^{(2)}$ is the Hankel function of the second kind.

Table 1 lists the wire parameters, attenuation $\alpha$ and characteristic impedance $Z_{\mathrm{c}}$, determined using (1) to (3), at $433 \mathrm{MHz}$ for the three different copper wire configurations used in the experiments. The characteristic impedance is a complex quantity and results show that impedance is mostly real for all three wires.

Figure 2 shows the attenuation and Figure 3 shows the

\begin{tabular}{|c|c|c|c|c|c|}
\hline \multirow[b]{2}{*}{ Name } & \multirow{2}{*}{$\begin{array}{l}\text { Conductor } \\
\text { radius }(a) \\
(\mathrm{mm})\end{array}$} & \multirow{2}{*}{$\begin{array}{l}\text { Insulation } \\
\text { radius }(b) \\
(\mathrm{mm})\end{array}$} & \multirow[b]{2}{*}{$(b / a)$} & \multicolumn{2}{|c|}{$f=433 \mathrm{MHz}$} \\
\hline & & & & $\begin{array}{c}\alpha \\
(\mathrm{dB} / \mathrm{m})\end{array}$ & $Z_{\mathrm{c}}(\Omega)$ \\
\hline $\begin{array}{l}\text { Wire 1 } \\
\text { (W1) }\end{array}$ & 0.45 & 1.3 & 2.88 & -32 & $62.5-\mathrm{j} 7.5$ \\
\hline $\begin{array}{l}\text { Wire } 2 \\
\text { (W2) }\end{array}$ & 0.3 & 0.75 & 2.5 & -35 & $61-j 7$ \\
\hline $\begin{array}{c}\text { Wire } 3 \\
\text { (W3) }\end{array}$ & 0.2 & 0.35 & 1.75 & -47 & $50-\mathrm{j} 5.5$ \\
\hline
\end{tabular}
real values of the characteristic impedance as a function of frequency ranging from 1 to $500 \mathrm{MHz}$ for the three wires

Tab. 1. Insulated wire parameters dimensions, attenuation and characteristic impedance at $433 \mathrm{MHz}$. 


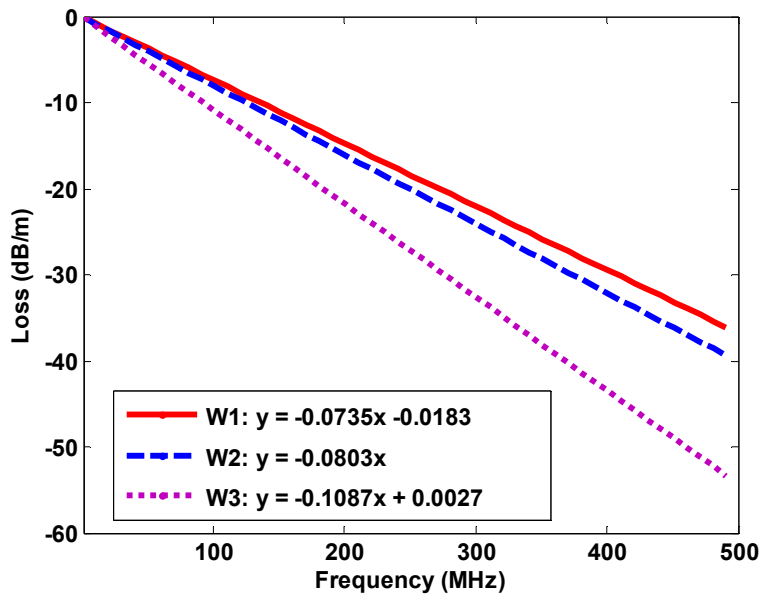

Fig. 2. Simulated attenuation coefficient $\alpha$ as a function of frequency, ranging from 1 to $500 \mathrm{MHz}$ for the three different types of wires listed in Tab. 1.

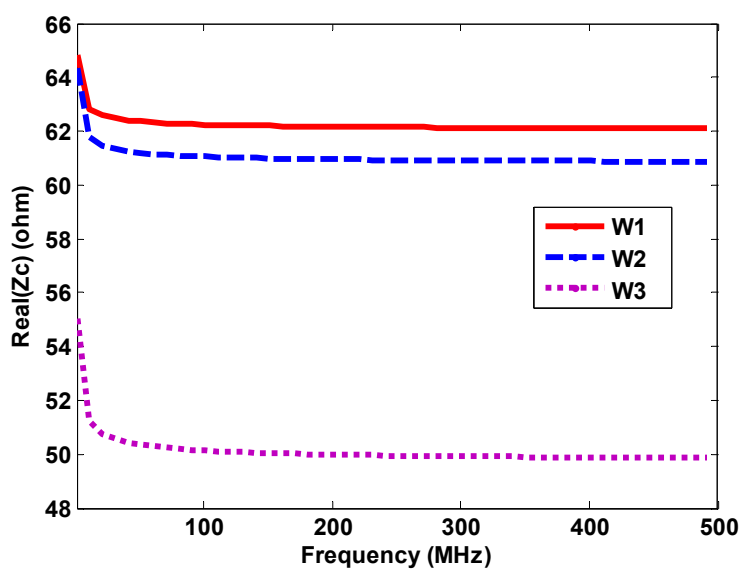

Fig. 3. Simulated characteristic impedance $Z_{\mathrm{c}}$ (Real) as a function of frequency, ranging from 1 to $500 \mathrm{MHz}$ for the three different wires listed in Tab. 1.

(see Tab. 1). Results show that the attenuation in the insulated wire increases considerably with increasing frequency.

The simulated results from Figs. 2 and 3 were determined using the measured conductivity and temperature of seawater $\left(6.45 \mathrm{~S} / \mathrm{m}\right.$ and $19^{\circ} \mathrm{C}$, respectively). These values were used to determine the permittivity of seawater using the Debye relaxation formulation [10], [11]. The factor $(b / a)$ is the ratio between the radii of the insulation and the inner conductor. This factor is a major contribution to the attenuation of the insulated wire in seawater (see Tab. 1). Wires 1 and 2 have a different cross-sectional area but their ratio $(b / a)$ is approximately the same. The difference in the attenuation coefficient of both wires is very small. The ratio $(b / a)$ for wire 3 is the lowest and it results in the highest attenuation. This shows that the higher the value of $(b / a)$, the lower the attenuation of the EM signal through the insulated wire.

The characteristic impedance of wire 3 is close to $50 \Omega$ over most of the frequency range. However, wire 1 and wire 2 show a slight mismatch which results in a small reflection of power between the insulated wire and the monopole antenna. Moreover, the movement of the float changes

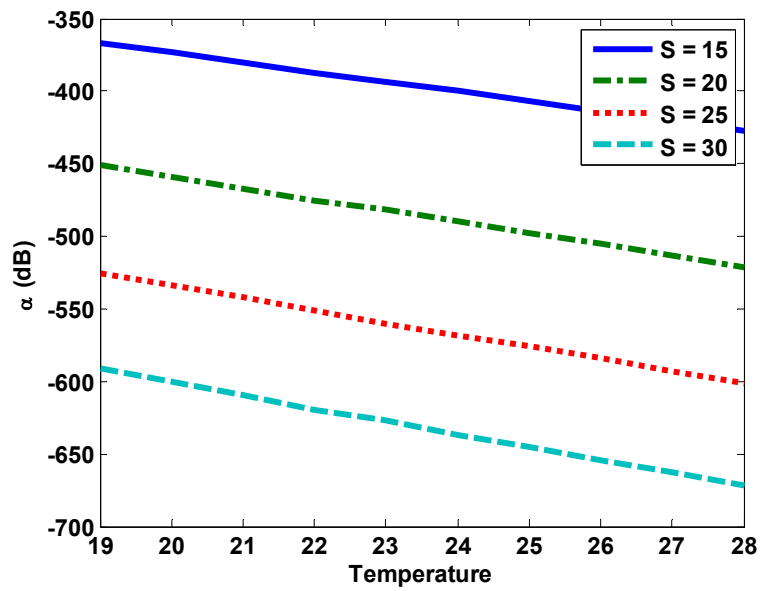

Fig. 4. Attenuation as function of temperature at $433 \mathrm{MHz}$ for selected values of salinity ( $\mathrm{S}$ in $\mathrm{ppt}$ ). The temperature range is from $19^{\circ} \mathrm{C}$ to $28^{\circ} \mathrm{C}$.

the length and orientation of the monopole antenna even under light wind and wave conditions. Impedance matching was performed by adjusting the length of the monopole antenna above seawater surface.

The relationship between seawater parameters is given by permittivity models. The values of salinity and temperature affect the electrical parameters of seawater which includes conductivity and permittivity. Figure 4 shows the effect of temperature change on the attenuation of EM wave at $433 \mathrm{MHz}$ for different values of salinity. The values have been calculated using the empirical formulations given by Klein-Swift model [11]. The results show that the attenuation increases with temperature for a particular value of salinity.

\section{Measurements}

Measurements were carried out in the laboratory to determine EM wave attenuation through a submerged insulated wire. In addition, a test was conducted to verify the effect of seawater conductivity on the resonance shift of a quarter wavelength monopole antenna. Moreover, field tests were performed to determine the propagation range of a floating monopole antenna fed by a submerged insulated wire. A comparison was also performed between three wires (see Tab. 1) and a shielded coax cable.

\subsection{Laboratory Measurements}

A rectangular plastic container was used for measuring the attenuation through insulated wires submerged in saline water in the laboratory. A wire $72 \mathrm{~cm}$ long was positioned in the center of the plastic container $(72 \mathrm{~cm} \times 36 \mathrm{~cm} \times 15 \mathrm{~cm})$. The insulated wire was connected to the center of a circular copper ground plane with diameter of $12 \mathrm{~cm}$ on either side of the plastic container through an SMA connector. Measurements were performed using a portable Vector Network Analyzer [15]. The saline solution was prepared from sodium chloride mixed with tap water (20 gms/ltr). A conductivity meter (WP 81 from TPS 
Pty Ltd) was used to monitor the conductivity, and salt was added step-wise until the conductivity reached a level of $5 \mathrm{~S} / \mathrm{m}$. The ground plane was attached on the outer side of the container and had no contact with the saline solution. The setup for the saline water container represents a two port network which was used to measure the transmission and reflection coefficients for the three insulated wires with different radii of insulation and inner conductor.

Scattering parameters for various wire configurations were measured $10 \mathrm{~cm}$ beneath the water surface. The reflection $\left(S_{11}\right)$ and transmission $\left(S_{21}\right)$ coefficients were measured over the frequency range of 1 to $500 \mathrm{MHz}$. The same parameters were measured in air. Figure 5 shows the return loss measurements for the three insulated wires. Measurements were performed with one end of the insulated wire connected to the VNA and the second end terminated with a matched load. The procedure was repeated for each wire.

All results show a resonant condition $\left(S_{11}\right.$ minimum) at $28 \mathrm{MHz}$ where the effective length of the wire is one quarter wavelength in the saline water. The wavelength in the saline container was calculated to be $10.34 \mathrm{~m}$. Since the wire length is $72 \mathrm{~cm}$, the relative permittivity of the saline water was $\varepsilon_{\mathrm{r}}=58.52$. The previous values of relative permittivity of seawater ranges between 72 to 80 [11]. This difference can be attributed to impedance mismatches during the measurements.

The $S_{11}$ results show that wire 1 with the highest (b/a) value has the lowest loss over most of the frequency range. In addition, the three insulated wires have almost the same resonant frequency. However, there is an offset in $\mathrm{dB}$ level for each wire. The $\mathrm{dB}$ offset between wire 1 and wire 2 is small since their $(b / a)$ ratio have similar values. Wire 3 shows the maximum loss due to the lowest $(b / a)$. These results show that the reflection depends significantly on the radius of insulation and the inner conductor. The frequency response of wire 3 shows minimal ripples since it is best matched to $50 \Omega$ (see Fig. 5). Since the length of the wire is $72 \mathrm{~cm}$, the attenuation $(\alpha)$ was calculated as $32 \mathrm{~dB} / \mathrm{m}$. The attenuation rate $\exp (-\alpha z)$ of the EM signal propagating in the saline container is given as $\left(E_{1} / E_{0}=0.025\right)$. From these results we can conclude that the dielectric constant $\left(\varepsilon^{\prime \prime} / \varepsilon^{\prime}\right.$ $>>100$ ) and the saline water behaves as a good conducting medium.

Figure 6 shows the transmission coefficient for the three insulated wires. Wires 1,2 and 3 show a loss of $25.4 \mathrm{~dB}, 26.7 \mathrm{~dB}$ and $31.6 \mathrm{~dB}$, respectively, at $433 \mathrm{MHz}$. As the length of the wire is $72 \mathrm{~cm}$, these results can be recalculated in $\mathrm{dB} / \mathrm{m}$ which matches closely the attenuation calculated in Sec. 2. The linear regression fit for the three wires shows a similar slope as the one from Fig. 2 $\left(r^{2}>0.96\right)$. The small difference in the calculated and measured attenuation rates are due to the difference in conductivity and temperature of water which affects the attenuation in the insulated wire. The conductivity in the saline container was $5 \mathrm{~S} / \mathrm{m}$ compared to $6.5 \mathrm{~S} / \mathrm{m}$ measured in the ocean. The reverse transmission $\left(S_{12}\right)$ and reflection

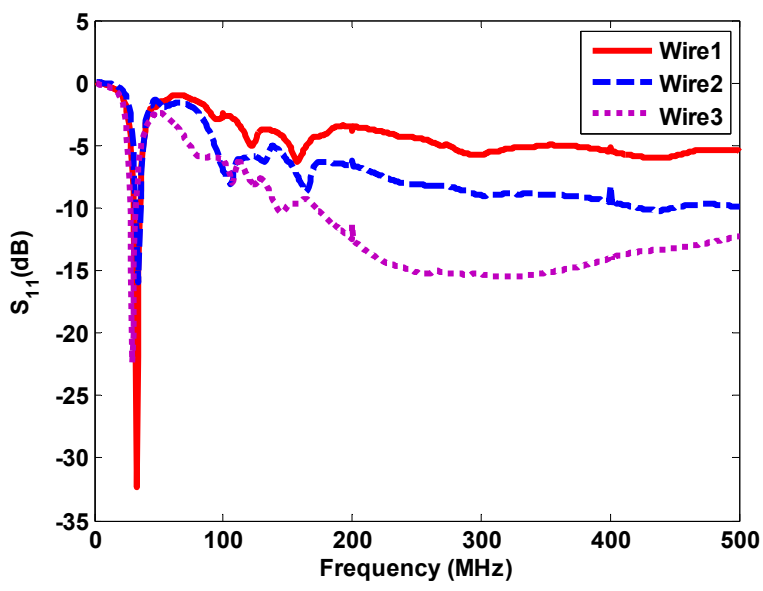

Fig. 5. Reflection coefficient $\left(S_{11}\right)$ for the three insulated wires (W1, W2 and W3) with a $50 \Omega$ matched termination.

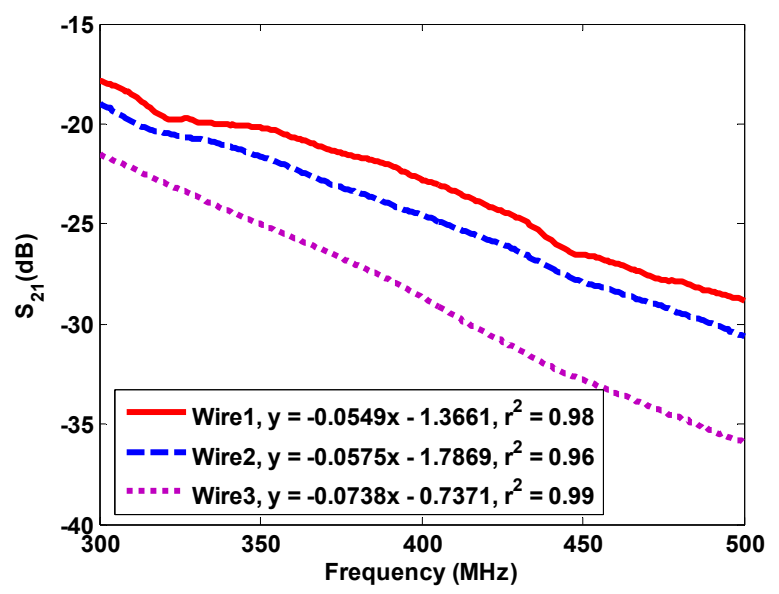

Fig. 6. Transmission coefficient $\left(S_{21}\right)$ for the three insulated wires (W1, W2 and W3).

$\left(S_{22}\right)$ parameters were also measured, however; the results are not reported since they are indistinguishable.

The results reported above show that the power in an insulated wire submerged in seawater attenuates significantly with slight changes in length and diameter of the wire. The conductivity and temperature of seawater affect the signal power for the submerged wire. These results are not significant if the same wire is in air or sand due to the low permittivity and conductivity values as compared to water.

The quarter wavelength in free space at $433 \mathrm{MHz}$ is $17 \mathrm{~cm}$. However, the seawater permittivity $\left(\varepsilon_{\mathrm{r}}=80\right)$ results in a shift of resonant frequency. This requires the antenna to be designed at a slightly higher frequency. The resonant shift due to the permittivity results in an antenna operating at required frequency i.e. $433 \mathrm{MHz}$. Figure 7 further explains the effect of seawater permittivity on the resonant frequency.

The monopole antenna was partially submerged in seawater and the conductivity of seawater was gradually increased from 1 to $4 \mathrm{~S} / \mathrm{m}$. Figure 7 shows the effect of seawater parameters on the antenna. The resonant frequency in air was recorded as $546 \mathrm{MHz}$. When the antenna 


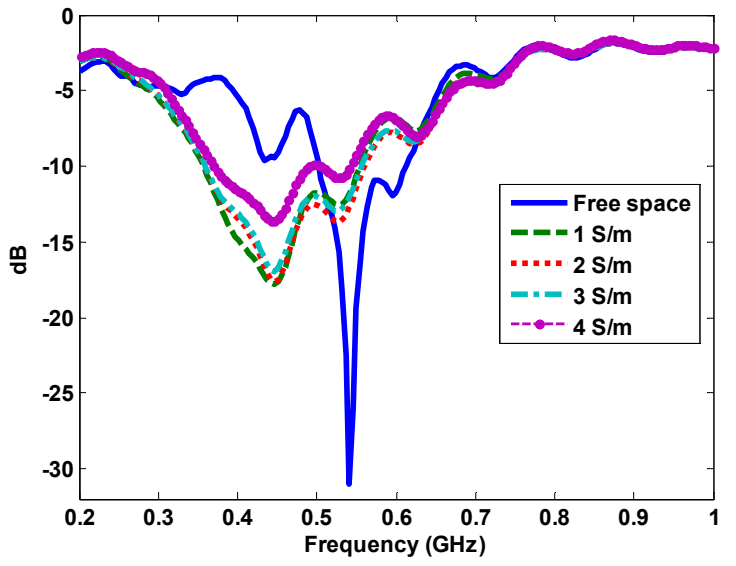

Fig. 7. The effect of seawater conductivity on the antenna resonant frequency measured as return loss.

was placed over the water surface with a conductivity of $1 \mathrm{~S} / \mathrm{m}$, the frequency shifted due to the high permittivity of seawater and resonated at $446 \mathrm{MHz}$ with a return loss of $17.66 \mathrm{~dB}$. When the conductivity was gradually increased to $4 \mathrm{~S} / \mathrm{m}$, the return loss changed significantly and a slight change in the resonant frequency was observed. According to Klein-Swift permittivity model, increasing the conductivity results in a partial change in permittivity ranging from 72 to 80 . Moreover, the resonant shift also depends on the operating frequency and is less significant at higher frequency bands [16].

\subsection{Field Measurements}

Propagation measurements across the water surface from a floating buoy were performed at a canal estate in Cleveland, Queensland, Australia [14], [17], where the water depth was between 1.5 to $3 \mathrm{~m}$. The transmitter node (Fig. 8) consists of a ground plane comprising the circuit board electronics $(60 \mathrm{~mm} \times 40 \mathrm{~mm})$.

This was connected to the insulated wires and the received power was measured with a stationary spectrum analyzer located $1 \mathrm{~m}$ above the water surface [18]. For comparison, a shielded coaxial cable was included in the measurements, the insulation around the protruding above water floating monopole was removed and measurements were performed with the bare inner conductor.

Figure 9 shows the set up for the propagation range measurements, where $d_{\text {LOS }}$ and $d_{\text {sr }}$ correspond to the lineof-sight and surface reflected distance between the antenna and the receiver, respectively. Here $h_{\mathrm{r}}$ is the height of the receiver above the seawater level, and $d$ is the horizontal distance between the antenna and the seashore.

The sensor was submerged in seawater with the monopole $(12.5 \mathrm{~cm})$ floating above the sea surface. The first measurement was performed with wire 1 at a separation distance of $5 \mathrm{~m}$ from the receiver (Fig. 10). The signal strength was $-77 \mathrm{dBm}$.

The floating monopole was moved away from the receiver step-wise until the signal level dropped below $-100 \mathrm{dBm}$ The same procedure was repeated for wires 2 and

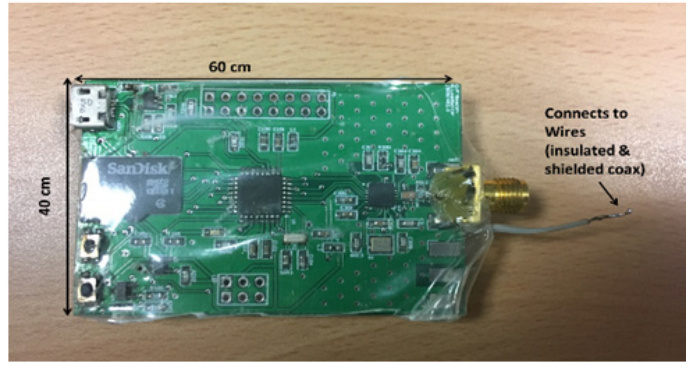

Fig. 8. Radio transceiver used for propagation range measurements operating at $433 \mathrm{MHz}$.

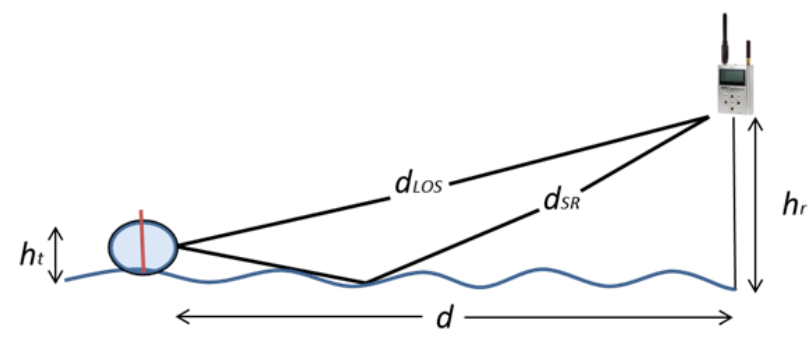

Fig. 9. Set up for propagation range measurements. The height of the transmitter is equal to the radius of the hemisphere, and the spectrum analyzer is placed onshore on a rock wall at $1 \mathrm{~m}$ above seawater level.

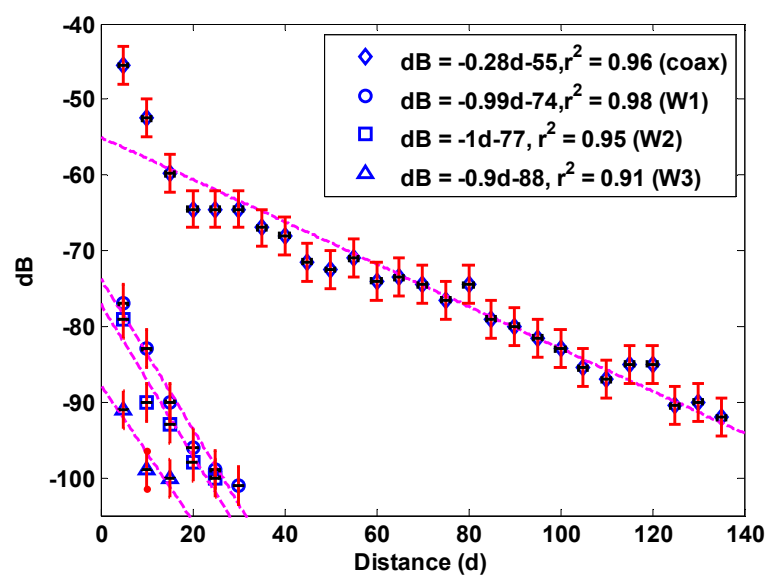

Fig. 10. Attenuation between a floating buoy (Coaxial cable, Wire1, Wire2, Wire3) and base station on the shore The measurements were made under light wind and wave conditions. The error bars show the RMS uncertainty in the measurements.

and 3. For wire 2, the signal level dropped to $-100 \mathrm{dBm}$ at a separation distance of $25 \mathrm{~m}$. For wire 3, the signal attenuation was much higher and it dropped at $15 \mathrm{~m}$. The attenuation of an EM signal in seawater depends on several factors which include sea roughness, height of the transmitter and the receiver, wind, and water direction, and most importantly, the operating frequency. The attenuation trends and variation in $\mathrm{dB}$ levels due to volatile and fluctuating seawater environment can be explained by an empirical model. The empirical modeling includes curve fitting the measured data to track the decrease in power with distance. Moreover, the mean and standard deviation of the received power is calculated to study the fluctuation in the received power. The linear regression lines were fitted to each measurement (see Fig. 10). The slope of the line for each 
test is almost $1 \mathrm{~dB} / \mathrm{m}$ for the surface propagation; however, there is a significant difference between the propagation ranges. The attenuation through wire 1 was the smallest (see Tab. 1), which results in more power at the floating monopole antenna. The attenuation through wire 2 is greater, and this results in a lower propagation range. Attenuation through wire 3 was the highest due to the lower ratio $(b / a)$, which resulted in the shortest propagation range.

This procedure was followed for the propagation range measurements using the shielded coaxial cable. The results show that the signal level dropped to a maximum of $-92 \mathrm{~dB}$ at a distance of $135 \mathrm{~m}$ which was almost the total width of canal estate. This shows that the shielded coax cable can transmit signal from the sea bed to the sea surface without any attenuation in signal power. A simple monopole antenna can be used to transmit the signal to an onshore base station resulting in increased propagation range.

The vertical error bars in Fig. 10 show a variation of $\pm 3 \mathrm{~dB}$ which reflects the standard deviation of the packet data. This variation was calculated using the packet data collected during the measurements. The statistical analysis of the packet data was developed as the one reported by Lee et al, in [8]. Figure 11 shows the histogram of the raw packet data collected during the experimental measurements, together with a mapping of the raw data using a Gaussian distribution function. The mean $(\mu)$ and standard deviation $(\sigma)$ for the packet data collected at a separation distance of $30 \mathrm{~m}$ was $-98.05 \mathrm{~dB}$ and $3 \mathrm{~dB}$, respectively. These values were used to plot the probability density function (PDF) that best fits the raw data. Furthermore, the packet loss was calculated as $1.73 \%$ for a separation distance of $30 \mathrm{~m}$ between transceivers. These experiments were performed in light wind conditions. The statistics reported above are valid for the sea state on the measurement day. A change in sea roughness would change the mean and standard deviation of the received power. Zhao et al. [9] reported a packet loss of $1.2 \%$ for smooth sea surface (wind speed $0 \mathrm{~m} / \mathrm{sec}$ ), however, the packet loss increased to $8.7 \%$ for a wind speed of $10 \mathrm{~m} / \mathrm{sec}$. This shows that wind speed has a considerable effect on link quality of a communication channel in the seawater environment. The results reported in Fig. 10 are for a floating sensor and a fixed onshore receiver. For a communication link between two floating sensors these statistics would further change and the link quality would deteriorate. Further analysis regarding link quality and packet loss between two floating buoys can be found in [14], [19]. Zhao et al. and Lee et al. performed experiments at $\mathrm{GHz}$, which resulted in more losses. EM wave attenuation is frequency dependent and higher frequencies propagating over water surface would attenuate more as compared to lower frequencies. Moreover, an increase in antenna height results in reduced losses and vice versa. Seawater communication is affected by several factors and a compromise between transmit power, operating frequency, antenna height and sea roughness is required for a good communication link. The proposed work is beneficial for shallow water coastal monitor-

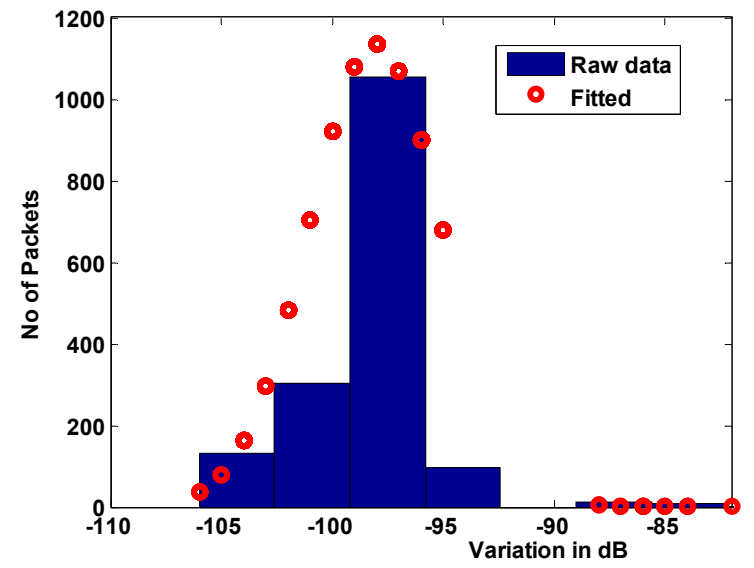

Fig. 11. Best fitted PDF with the experimental data having mean $(\mu=-98 \mathrm{~dB})$ and standard deviation $(\sigma=3 \mathrm{~dB})$.

ing where considerable propagation range can be achieved at $433 \mathrm{MHz}$.

\section{Conclusion}

The characteristics of an insulated wire submerged in sea water at $433 \mathrm{MHz}$ were measured and analyzed. Results showed that the attenuation in the insulated wire depends on the ratio of the radii of insulation and inner conductor for a particular frequency and sea state conditions. The surface propagation range was $30 \mathrm{~m}$. This distance can be extended by changing the wire cross-section and increasing the transmitter power. The length of insulated wire can also be extended to approximately $2 \mathrm{~m}$. There is a compromise, however, between the length of insulated wire and the surface propagation distance. Increasing the length of the insulated wire would reduce the surface propagation range for a fixed transmitter power output. Floating monopoles can be effectively used for shallow water coastal monitoring since they are low cost, low power and have a considerable propagation range that depends upon the operating frequency. The shielded coaxial cable shows almost no loss when immersed in seawater and so the surface propagation extends to much longer distances across the surface. The low cost, insulated wire solution is simple to deploy and would be suitable to closely spaced sensor nodes. For much larger distance and deeper sensors, the coaxial solution is preferable.

\section{Acknowledgments}

Z. M. Loni would like to thank Griffith University for providing scholarship to pursue his $\mathrm{PhD}$ studies at the Department of Engineering.

\section{References}

[1] LIU, L., ZHOU, S., CUI, J. Prospects and problems of wireless communication for underwater sensor network. Wireless 
Communications and Mobile Computing (special issue on Underwater Sensor Networks: Architectures and Protocols), 2008, vol. 8, no. 8, p. 977-994. DOI: 10.1002/wcm.654

[2] HEIDEMANN, J., STOJANOVIC, M., ZORZI, M. Underwater sensor networks: applications, advances and challenges. Philsophical Transactions of the Royal Society A, 2012, vol. 370, no. 1958 , p. $158-175$. DOI: $10.1098 /$ rsta.2011.0214

[3] AL SHAMMAA, A. I., SHAW, A., SAMAN, S. Propagation of electromagnetic waves at $\mathrm{MHz}$ frequencies through seawater, IEEE Transactions on Antennas and Propagation, 2004, vol. 52, no. 11, p. 2843-2849. DOI: 10.1109/TAP.2004.834449

[4] ABDOU, A., SHAW, A., MASON, A., et al. Wireless sensor network for underwater communication. In IET Conference on Wireless Sensor Systems. London (UK), 2012, p. 3-8. DOI: 10.1049/cp.2012.0579

[5] JIMENEZ, E., QUINTANA, G., MENA, P., et al. Investigation on radio wave propagation in shallow seawater: Simulations and measurements. In IEEE Conference on Underwater Communications and Networking. Lerici (Italy), 2016. DOI: 10.1109/UComms.2016.7583453

[6] DATSKO, V. N. Surface electromagnetic waves on seawater. Journal of Communication Technology and Electronics, 2016, vol. 61, no. 1, p. 10-11. DOI: 10.1134/S1064226916010034

[7] MILFORD, G. N., DUNBAR, R. M. Electromagnetic propagation to VHF frequencies along an insulated wire antenna immersed in saltwater. In IEEE Conference on Military Communications and Information Systems (MilCIS). Canberra (Australia), 2011, 6 p. DOI: 10.1109/MilCIS.2011.6470390

[8] LEE, Y. H., MENG, Y. S. Empirical modelling of ducting effects on a mobile microwave link over a sea surface. Radionegineering, 2012, vol. 21, no. 4, p. 1054-1059.

[9] ZHAO, X., HUANG, S., FAN, H. Influence of sea surface roughness on the electromagnetic wave propagation in the duct environment. Radionegineering, 2010, vol. 19, no. 4, p. 601-605.

[10] DEBYE, P. Polar Molecules. Williamsburg (USA): Dover, 1945.

[11] KLEIN, L., SWIFT, C. T. An improved model for the dielectric constant of seawater at microwave frequencies. IEEE Journal of Oceanic Engineering, 1977, vol. 2, no. 1, p. 104-111. DOI: 10.1109/JOE.1977.1145319

[12] KING, W. P., SMITH, G. S. Antenna in Matters. London (UK): MIT Press, Cambridge, 1981. ISBN: 0262110741

[13] HERTEL, W., SMITH, G. S. The insulated linear antenna revisited. IEEE Transactions on Antennas and Propagation, 2000, vol. 48, no. 6, p. 914-920. DOI: 10.1109/8.865224

[14] LONI, Z. M., ESPINOSA, H. G., THIEL, D. V. Floating monopole antenna on a tethered subsurface sensor at $433 \mathrm{MHz}$ for ocean monitoring applications. IEEE Journal on Oceanic Engineering, 2017, vol. 42, no. 4, p. 818-825. DOI: 10.1109/JOE.2016.2639111

[15] N9923A Keysight Technologies. [Online]. Cited 2017-09-26. Available at: https://www.keysight.com/en/pdx-x201782-pnN9923A/fieldfox-handheld-rf-vector-network-analyzer-4-ghz-and6-ghz?cc $=$ GR\&lc $=$ eng $\%$ E2 $\% 80 \% 9 D$

[16] JAMES, D. A., GALEHAR, A., THIEL, D. V. Mobile sensor communications in aquatic environments for sporting applications, Procedia Engineering, 2010, vol. 2, no. 2, p. 3017-3022. DOI: 10.1016/j.proeng.2010.04.104

[17] BROWN, K., ROOT PTY LTD. Geo technical and investigation report. Raby Bay canal batter stability update, 24 June 2013.

[18] Proteck $3290 \mathrm{~N} 100 \mathrm{KHz}, 2.9 \mathrm{GHz}$ RF Field strength analyzer. [Online]. Cited 2017-09-26. Available at: http: //www.testequipmentdatasheets.com/protek-3290n-hand-held29ghz-rf-signal-strength-analyzer/
[19] JACKSON, N. C., THIEL, D. V. ISM band $2.45 \mathrm{GHz}$ propagation studies in a coastal environment. In 2015 International Symposium on Antennas and Propagation (ISAP). Hobart (TAS, Australia), 2015, p. 663-666. ISBN: 978-4-8855-2302-1

\section{About the Authors ...}

Zia M. LONI received his bachelor degree in Telecommunications Engineering from the University of Engineering and Technology Peshawar, Pakistan, in 2006, the master's degree in Electronics Engineering from Mohammad Ali Jinnah University Islamabad, Pakistan, in 2010. He is currently working towards his Ph.D. degree at Griffith University, Brisbane, Australia. He is also working as a sessional instructor in the School of Engineering, Griffith University. From 2010 to 2015, he has been a lecturer with COMSATS Inst. of Information Technology, Abbottabad, Pakistan. His research interests include electromagnetic wave propagation, antennas, remote sensing, and wireless sensor networks.

Hugo G. ESPINOSA received the degree in Electronics and Telecommunications Engineering from the Monterrey Inst. of Technology and Higher Education, Mexico, in 1998, the master's degree from the University of Sao Paulo, Brazil, in 2002, and the Ph.D. degree (summa cum laude) from the Technical University of Catalonia, Spain, in 2008, both in Electrical Engineering. He joined the Federal Polytechnic School of Lausanne, Switzerland, in 2006, for a four-month research stay. From 2009 to 2010, he has been a Post-Doctoral Fellow with the Physical Electronics Dept., School of Electrical Engineering, Tel Aviv University, Israel. Since 2011, he has been with the School of Engineering at Griffith University, Brisbane, Queensland, Australia, where he is currently a Lecturer in Electronic Engineering. His research interests include computational electromagnetics, wave propagation, electromagnetic geophysics, wireless sensor networks, and wearable sensor technology for human monitoring. Dr. Espinosa serves as a Senior Member of the IEEE.

David V. THIEL received the degree in Physics and Applied Mathematics from the University of Adelaide, Adelaide, SA, Australia, and the master's and Ph.D. degrees from James Cook University, Townsville, QLD. He is currently the Deputy Head of School (Research) with Griffith University, Brisbane, QLD, Australia. He is a Fellow of the Institution of Engineers, Australia, and a Chartered Professional Engineer in Australia. His research interests include electromagnetic geophysics, sensor development, electronics systems design and manufacture, antenna development for wireless sensor networks, environmental sustainability in electronics manufacturing, sports engineering, and mining engineering. He authored the book Research Methods for Engineers, and co-authored a book on Switched Parasitic Antennas for Cellular Communications. Prof. Thiel has authored six book chapters, over 130 journal papers, and has co-authored more than nine patent applications. 